\title{
O Poema-Canção e a Crônica-imagem de Chico Buarque ${ }^{1}$
}

\author{
Juliana Cavalcanti FIGUEIRÊEO ${ }^{2}$ \\ Marcelo PESSOA ${ }^{3}$ \\ Universidade do Estado de Minas Gerais, Frutal, MG
}

\section{Resumo}

O presente trabalho está centrado nos estudos jornalísticos e literários, aos quais estão atrelados aos pressupostos dos Estudos Culturais e da Análise do Discurso. O objetivo da pesquisa proposta é delimitar e interpretar o modo como são realizadas as releituras dos poemas-canções de Chico Buarque, na obra A Imagem do Som de Chico Buarque. Tal livro apresenta uma transposição de poemas para imagens, com o que chamaremos em nossa pesquisa de crônicas-imagens. O poeta-compositor em voga, no cenário da MPB - Música Popular Brasileira -, se nos apresenta como artista sui generis, ao conjugar em sua obra poético-musical, tanto elementos próprios da produção textual em prosa, quanto dos expedientes típicos da música, reafirmando-se assim, como um dos maiores representantes da literatura e da música nacional.

Palavras-chave: canção; Chico Buarque ; crônica; imagem.

\section{Introdução}

\subsection{Particularidades Linguísticas do Problema Pós-colonial e Ditatorial na obra de} Chico Buarque: a cronicização do Cotidiano Brasileiro

De um lado, temos que o poder interno de ataque da linguagem de Chico Buarque se revela como mola propulsora que o lança fora de uma referencialidade histórica e geográfica e o aproxima de uma atitude tipicamente estética.

\footnotetext{
${ }^{1}$ Trabalho apresentado no DT 1 - Jornalismo do XVII Congresso de Ciências da Comunicação na Região Sudeste realizado de 28 a 30 de junho de 2012.

2 Estudante de Graduação $7^{\circ}$. Semestre do Curso de Comunicação Social da UEMG-Frutal, bolsista PIBIC UEMG/CNPq email: juliana.c.f@ hotmail.com

${ }^{3}$ Orientador do trabalho. Professor do Curso de Comunicação Social da UEMG-Frutal, bolsista PDJ CNPq email: mpmarcelopessoa@yahoo.com.br
} 
De outro lado, vemos que a tônica preferencial do olhar de Chico Buarque ao cotidiano brasileiro insiste na abordagem das diferenças que envolvem o colonizado em relação ao colonizador.

Em nosso trabalho, acreditamos que, o que predominantemente ocorre nos textos de Chico Buarque, é a dissensão dual entre o típico denuncismo retórico latinoamericano (como desejava a esquerda intelectual dos anos sessenta) e a manipulação estética da linguagem (à moda de Chico Buarque, de Caetano Veloso, dos tropicalistas e dos adeptos da Antropofagia oswaldiana).

A obra central das nossas investigações, A Imagem do Som de Chico Buarque, com texto e diagramação produzidos pelo Projeto Imagem do Som, é composta por 80 poemas-canções relidos, denominados em nossa pesquisa como crônicas-imagens. Acreditamos que Chico Buarque teria, em algumas de suas letras, deixado transparecer, de algum modo, elementos dessas influências e efervescências socioculturais, influências as quais os artistas nos revelaram na obra A Imagem do Som de Chico Buarque, em forma de imagens. Percebemos que, no caso de Chico Buarque, o que pode ter ocorrido em seu processo criativo é que, ao lado de sua preocupação linguística, pode existir subentendido subjetividades registradas.

Emerge, então, a possibilidade de uma reescritura ou releitura da própria conjuntura social e histórica da latinidade na América do Sul, fato que Eduardo Galeano (2002) denomina de "veias abertas da América Latina", e aos quais Jameson nos coloca nestes termos:

[...] a ênfase no dialógico permite-nos reler ou reescrever as próprias formas hegemônicas, elas também podem ser apreendidas como um processo de reapropriação, de neutralização, de cooptação e de transformação de classe, e de universalização cultural de forma que originalmente expressavam a situação de grupos populares, subordinados ou dominados (JAMESON, 1992, p. 79).

Percebemos essa particularidade nas canções de Chico Buarque. Elas quase que obrigam o leitor a entender os textos como representativos, de um lado, de um contexto reconhecível - o Brasil e a América Latina -, e, de outro lado, de si mesmas (portanto, como objetos estéticos), uma vez que a obra poético-musical se desvincula da "matriz" linguística escrita e se presta às diversas releituras que têm sido realizadas na modalidade conto, imagem, filme etc. 
Desse modo, temos que os textos de Chico Buarque chamam a atenção nem tanto por causa de seu conteúdo de entretenimento, mas como estratégias de linguagem para construir o significado alegórico da poesia cantada, encenada, romanceada etc.

O discurso de Chico Buarque é sintagmático. É construído todo por meio de encadeamentos de metáforas, demonstrando uma série de ramificações alegóricas que representam a própria natureza do objeto artístico - na literatura, na música, na imagem.

Com um procedimento de contínua reinvenção, que envolve o leitor / plateia na concatenação de sentidos de sua sintaxe identitária e cultural, o autor cria uma estrutura dialógica: é a dialética, afinal, que se opera entre leitor e obra, recuperando a dialética entre colonizador e colonizado, entre linguagem primitiva e (interlíngua) linguagem pós-colonial, entre objetividade e subjetividade, fato que nos abre a vertente sociológica para a análise linguística das letras das canções. Ambos - autor/obra e leitor/significação - interagem, se negam, se respeitam, se violam, mas, acima, de tudo, absorvem-se reciprocamente.

\section{Metodologia}

Em nosso trabalho foi feito o levantamento sistemático de material bibliográfico, envolvendo-se as várias mídias de veiculação - impressas e eletrônicas. Posteriormente, procedemos às leituras bibliográficas, pesquisas em vídeos, CDs, DVDs, investigação de dados na internet. Confecção de fichamentos, resenhas críticas e resumos a partir dos textos lidos e confrontados. Tais etapas contemplaram as seguintes ações:

a) Levantamento sistemático de material bibliográfico, envolvendo-se as várias mídias de veiculação - impressas e eletrônicas;

b) Posteriormente, procedeu-se à catalogação do material coletado;

c) Em seguida, foi realizada a confecção de uma listagem do material bibliográfico coletado sobre o assunto crônica, ditadura militar e poesia cantada;

d) Na sequência, realizamos uma seleção e listagem dos temas, títulos e capítulos relacionados com a abrangência do tema poema-canção e ditadura militar no Brasil e, finalmente,

e) Operacionalizou-se a confecção de resenhas, a partir das quais pudemos nos apropriar dos conteúdos lidos, transformando-os em material subsidiário para 
contribuir para com a nossa formação na graduação e na produção de conhecimento, via participação em eventos acadêmicos, sociais, científicos, artísticos e culturais.

\section{Discussão e Revisão Bibliográfica}

\subsection{Crônica: a importância do ponto de vista da Teoria e da Crítica Literária}

O propósito neste ponto de nossa investigação é realizar uma revisão de parte do estatuto da teoria e da crítica literária do século XX, a partir do recorte da pertinência dessa revisão para a intersecção com o pensamento corrente sobre a crônica e suas diversas classificações e possíveis relações intertextuais.

Compreendidas como pertencentes ao gênero literário e, de alguma maneira, discutidas, mesmo que indiretamente, pela tradição crítica, verifica-se que a crônica tende a aparecer nos discursos tradicionais da crítica normalmente sob a designação genérica de textos em prosa, mesmo que seus elementos essenciais também estejam presentes nas modalidades narrativas mais tradicionais, como contos e romances.

Isso também ganha relevante importância se considerarmos o fato de que "A história de nossa literatura se inicia, pois, com a circunstância de um descobrimento: oficialmente, a Literatura Brasileira nasceu da crônica” (SÁ, 2008, p. 07).

\subsection{Crônica: o que nos dizem os críticos literários a respeito dela}

Nas observações biográficas e históricas sobre os precursores da crítica literária brasileira, verifica-se que em seus discursos, a crônica, enquanto vertente literária atinge seu ápice de maturidade em meados do século XX, fundamentalmente com a cisão com o seu passado de "crítica de rodapé". A chamada prática da "crítica de rodapé", gênero embrião e, portanto, aparentado da crônica e do ensaio, embora confeccionada com o propósito específico de defender ou digladiar com a produção cultural de uma época, não deixou de fazer, mesmo que não intencionalmente, uma crônica histórico-literária ${ }^{4}$ e cultural bastante paradigmática de toda uma geração de

\footnotetext{
${ }^{4}$ Do ponto de vista histórico, crônica efetivamente significa narração de fatos, de forma cronológica, como documento para a posteridade. A produção dos cronistas foi legitimada pela literatura que a
} 
intelectuais no Brasil. E nisso, quando se apropria dos fatos imediatos do cotidiano, ainda que essa apropriação diga respeito a apenas uma parcela de intelectuais, a aproxima embrionariamente das crônicas contemporâneas:

Os anos 40 e 50 estão marcados no Brasil pelo triunfo da "crítica de rodapé". O que significa dizer: por uma crítica ligada fundamentalmente à não-especialização da maior parte dos que se dedicam a ela, na sua quase totalidade bacharéis; ao meio em que é exercida, isto é, o jornal o que lhe traz, quando nada, três características formais bem nítidas: a oscilação entre a crônica e o noticiário puro e simples, o cultivo da eloquência, já que se tratava de convencer rápido leitores e antagonistas, e a adaptação às exigências (entretenimento, redundância e leitura fácil) (SUSSEKIND, 1993, p. 14).

A crônica, portanto, inicialmente compreendida como de um lado descendente dos "rodapés", lembra Afrânio Coutinho (Apud MELO, 2003, p. 153), teria por outro lado, em sua face ascendente, o escritor Machado de Assis, pois foi o lado cronista machadiano que imprimiu a esse tipo de texto seus primeiros e melhores traços de personalidade, tipo de narrativa na qual, aliás, Machado confessava-se escrevendo "brasileiro" 5", isto é, numa língua brasileira, não portuguesa, nem de origem indígena.

Dentro do universo de autores que discursam diretamente sobre a crônica até agora apresentados, tais como Davi Arrigucci Jr., Jorge de Sá, Antônio Cândido, José Marques de Melo, Massaud Moisés e outros, até encontramos divergências deles entre si, principalmente quanto à unanimidade do gênero crônica como literatura.

Contudo, advertimos que todos concordam em dizer que a crônica, quer seja elencada como gênero jornalístico ou literário, quer seja classificada como mais ou menos dotada de poeticidade, sem dúvida tem suas origens vinculadas a certos aspectos da oralidade, como vimos com Antônio Cândido, bem como às antigas narrativas, aos textos de informação, ao folhetim, e ainda aos primórdios da crítica literária.

recolheu como representativa da expressão de uma determinada época. [...] Foi nesse sentido de relato histórico que a crônica chegou ao jornalismo (MELO, 2003, p. 149).

${ }^{5}$ No entender de Afrânio Coutinho,a crônica adquire personalidade com Machado de Assis,que, ao praticar esse gênero, confessava-se escrevendo "brasileiro" (MELO, 2003, p. 153). 
Desse modo, outro pensador que destacamos nesse tocante, é Afrânio Coutinho, crítico que se debruçou sobre a crônica, e de quem também se percebe dizer que a crônica pôde ganhar força como fenômeno literário, uma vez que ela estava, devido à própria natureza inventiva de seus autores e de seus temas, intensamente permeada de fragmentos da práxis filosófica e social contemporâneas.

E esse dizer de Afrânio até nos ajuda a entender um pouco mais da migração da escrita para a canção empreendida por parte de alguns poetas e artistas, como nos disse Wisnik (2004) ${ }^{6}$ :

Tão característica é a intimidade do gênero com seu veículo natural [o jornal] que muitos críticos se recusam a ver na crônica, a despeito da voga de que desfruta, algo durável e permanente, considerando-a uma arte menor. Para Tristão de Athayde "uma crônica num livro é como um passarinho afogado". De qualquer modo, se aceite ou não a permanência da crônica, é certo que ela somente será considerada gênero literário quando apresentar qualidade literária, libertando-se de sua condição circunstancial pelo estilo e pela individualidade do autor (COUTINHO, 1986, p. 123).

Os Estudos Culturais podem melhor atestar e dar conta de explicitar em suas "relações interdisciplinares", as nuances e posturas individuais e coletivas socioculturais apreendidas pelas crônicas contemporâneas e tão em voga sobre os discursos da modernidade e da pós-modernidade.

Desse modo, demonstramos nuances e prováveis lacunas a servirem de objetos de estudo para a abordagem da crônica-canção e da crônica visual de Chico Buarque.

Observamos, entretanto, nesse sentido, que os autores até aqui discutidos, mais se ratificam mutuamente do que divergem quanto à crônica e seus pilares fundamentais. O que, aliás, para nosso estudo, se traduz num grande ganho.

\footnotetext{
${ }^{6}$ [...] Arnaldo Antunes faz uma ponte entre poesia concreta e o rock, desenvolvendo a partir daí uma poética pessoal que trabalha simultaneamente com poesia-livro, vídeo e música (p. 217). Se pensarmos também no fato de que a obra de Caetano Veloso dá a esse processo a sua visibilidade máxima, no fato de Chico Buarque ter escrito um importante romance, Estorvo, e Júlio Bressane ter feito um filme, Tabu, [...], podemos postular que se constitui no Brasil, efetivamente, uma nova forma da "gaia ciência", isto é, um saber poético-musical que implica uma refinada educação sentimental [...] (WISNIK, 2004, p 218).
} 


\subsection{Trânsito semiótico: as crônicas-imagens}

A transposição dos poemas-canções de Chico Buarque em imagens na obra $A$ Imagem do Som de Chico Buarque permite-nos desatar subjetividades, devido à transmissão de significados que a crônica-visual carrega.

Com esse entrecruzamento cremos ajudar-nos-á a compreender satisfatoriamente as lacunas psicossociais e culturais a nosso ver surgidas durante o trânsito semiótico operacionalizado entre a modalidade poema e a modalidade imagem.

Tais imagens criadas pelos artistas plásticos carregam significados distintos, em alguns casos o poema-canção é retratado de forma literal, enquanto outros necessitam de uma análise criteriosa dentro do contexto que se encontram.

\section{Caso- exemplo:}
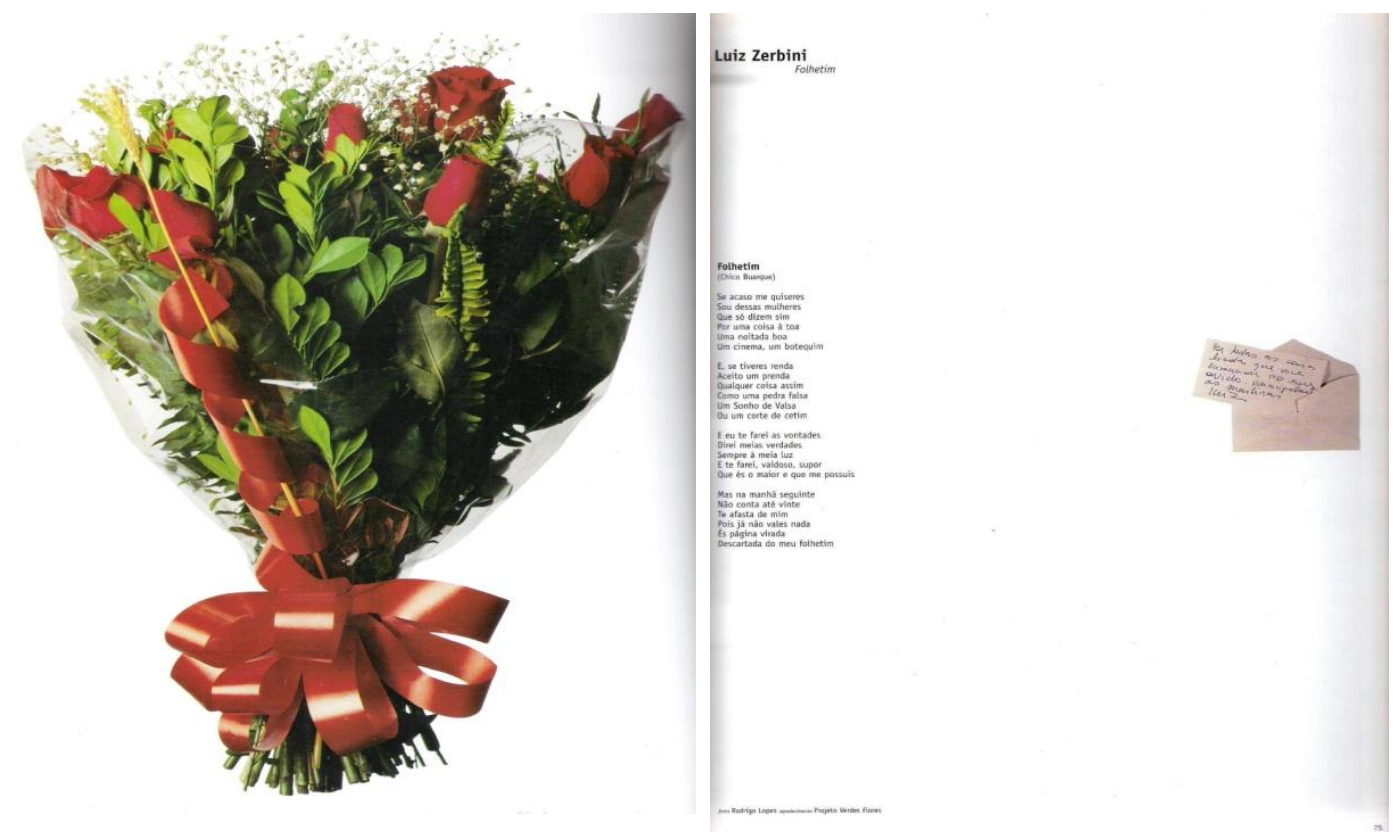

O poema-canção acima retratado é "Folhetim" (Chico Buarque/ 1977), a reprodução imagética da composição de Chico foi representada pelo artista plástico Luiz Zerbini. Este último nos apresenta "Folhetim" através de um buquê de rosas e um cartão.

A crônica-visual do caso-exemplo acima é carregada de significados, ao decompor "Folhetim" concluímos que trata-se de uma mulher da boemia, decidida que seus amores duram apenas uma noite. Tal mulher comenta sobre a possibilidade de receber presentes de seus admiradores, o artista a presenteia com o buquê e o cartão com os seguintes dizeres: "Por todas as coisas lindas que você sussurrou no meu ouvido, principalmente as mentiras." 
Além disso, as rosas vermelhas representam paixão e feminilidade, a beleza que exibem dura pouco tempo fazendo com que acabem perdendo o encanto e morrendo rapidamente.

\section{Resultados Parciais}

Notamos que os autores pesquisados e tidos como estudiosos do gênero crônica, de alguma maneira, apresentaram classificações um tanto quanto abrangentes sobre esse modelo textual - a crônica. Eles dispuseram o assunto sob a designação de vários nomes. Como crônica-poema, crônica-conto, vimos por parte de Massaud Moisés; crônica sentimental, crônica satírico-humorística, em Luiz Beltrão; crônica exposição poética, crônica biografia lírica, da lavra de Antonio Cândido, e, finalmente, crônicapoema-em-prosa, a qual nos chegou por Afrânio Coutinho.

Essas subdivisões, diz-nos José Marques de Melo, autor que nos apresentou a todas elas, não têm "a pretensão de criar categorias, mas tão somente destacar diferenças entre os modernos cronistas brasileiros" (MELO, 2003, p. 159).

Embora despretensiosa no seu propósito, contudo, tal categorização não deixou de nos abrir um importante leque de investigação jornalístico-literária que abarcou desde a crônica escrita em prosa, passando por modalidades mistas de prosa e verso ${ }^{7}$, recorrentes nos jornais pela pena de um Drummond, de um Braga, de um Cony ou João do Rio.

De mais a mais, dos autores por nós selecionados para sustentar nossos argumentos durante a aproximação dos conteúdos das crônicas em prosa com as letras de Chico Buarque, tornou-se patente em suas exposições a ideia da possibilidade de que as crônicas possam conter, com bastante frequência até, alguma poesia, alguma visualidade, independentemente de seu formato de manifestação - prosa, verso.

Igualmente, ao mesmo tempo em que os críticos admitem, portanto, a existência de uma crônica-poema, de uma crônica-poema-em-prosa e de uma crônica-exposição poética, por exemplo, não nos dizem haver, ao menos diretamente, a obrigatoriedade de que tais textos devam ser escritos efetivamente em prosa.

\footnotetext{
${ }^{7}$ É perfeitamente compreensível que os cronistas literários fossem igualmente poetas, com a circunstância de que algumas de suas poesias narrativas não deixam de ter certo ar de crônica. Crônica em verso - para mencionar apenas um caso - era o que fazia Joaquim Norberto, quando, no poema "A Confissão", descreveu o Rio de Janeiro do tempo do velho entrudo (COUTINHO, 1986, p. 123-124).
} 
Desse modo, supomos que o histórico do confeccionar crônica em versos, dada a estatura da prática de um Drummond, de um Rubem Braga, do apego en passant ao estilo por parte de um Joaquim Norberto, apesar de contarem como exemplares quase que isolados na tradição em versos do gênero crônica, entendemos que ainda assim eles podem ajudar-nos a validar nossa chancela de que Chico Buarque compõe crônicascanções e, mais precisamente, crônicas-visuais.

Para ele, a fidelidade para com o cotidiano de um lado, e a afeição à crítica social de outro, seriam dois dos elementos preponderantes para a constituição da crônica como texto social. Assim, as crônicas cantadas de Chico Buarque podem alinhar-se perfeitamente ao calor das ruas e movimentos socioculturais e serem transformadas, como o foram, em crônicas-imagens na obra de TABORDA (1999).

\section{Referências bibliográficas}

ARRIGUCCI Jr., Davi. Braga de Novo Por Aqui. In: . Enigma e comentário. São Paulo: Cia. das Letras, 2001a, p. 29-50.

ARRIGUCCI Jr., Davi. Fragmentos sobre a Crônica. In: São Paulo: Cia. das Letras, 2001b, p. 51-66.

. Enigma e comentário.

BOSI, Alfredo. História Concisa da Literatura Brasileira. Rio de Janeiro: Cultrix, 1994.

BUARQUE, Chico. Estorvo. São Paulo: Cia. das Letras, 1991.

CHAVES, Rita; \& MACÊDO, Tânia (org.). Literaturas em Movimento - hibridismo cultural e exercício crítico. São Paulo: Arte \& Ciência, 2003.

COUTINHO, Afrânio. Ensaio e Crônica. In: A Literatura no Brasil. V. 6, 3. ed. Rio de Janeiro: José Olympio; Niterói: EDUFF, 1986.

COUTINHO, Eduardo. O Pós-Modernismo e a Literatura Latino-Americana Contemporânea. In: ___ Literatura Comparada na América Latina. Rio de Janeiro: EdUERJ, 2003, p. 103-112.

GALEANO, Eduardo. As Veias Abertas da América Latina. Rio de Janeiro: Paz e Terra, 2002.

GONÇALVES, Rita de Cássia Sanches. A Arte drummondiana na era de supremacia midiática. (Dissertação de Mestrado). UEL - Universidade Estadual de Londrina, Londrina, 2004.

JAMESON, Fredric. O Inconsciente Político - a narrativa como ato socialmente simbólico. São Paulo: Ática, 1992. 
KONZEN, Paulo Cezar. Crônica e Crítica: comicidade e contestação em Luis Fernando Veríssimo. (Dissertação de Mestrado). UEL - Universidade Estadual de Londrina, Londrina, 2000.

LAFETÁ, João Luiz. Modernismo: projeto estético e ideológico. In: 1930: A Crítica e o Modernismo. São Paulo: Duas Cidades, 2000, p. 19-38.

LIMA, Luiz Costa. O New Criticism nos Estados Unidos. In: Teoria da Literatura em suas Fontes. Rio de Janeiro: Civilização Brasileira, 2002a, p. 551-583.

LIMA, Luiz Costa. A análise sociológica da literatura. In: Teoria da Literatura em suas Fontes. Rio de Janeiro: Civilização Brasileira, 2002b, p. 661-687.

LIMA, Luiz Costa. Estruturalismo e Crítica Literária. In: Teoria da Literatura em suas Fontes. Rio de Janeiro: Civilização Brasileira, 2002c, p. 777-815.

MELLO, José Eduardo Homem de. Chico Buarque. In: Música Popular Brasileira. São Paulo: Melhoramentos / USP, 1976, p. 23-24.

MELO, José Marques de. A Crônica. In: Jornalismo Opinativo - gêneros opinativos no jornalismo brasileiro. Campos do Jordão: Mantiqueira, 2003, $3^{\text {a }}$ ed., p. 148162.

SÁ, Jorge de. A Crônica. São Paulo: Ática, 2008.

SILVA, Ana Paula Ramão da. Imagens do mar nas crônicas de Rubem Braga. (Dissertação de Mestrado). UEL - Universidade Estadual de Londrina, Londrina, 2005.

SIMON, Luiz Carlos Santos. Além do Visível: Contos Brasileiros e Imagens na Era do Pós-Modernismo. UERJ: Tese de Doutorado, 1999.

SIMON, Luiz Carlos Santos. Do Jornal ao Livro: A Trajetória da Crônica entre a Polêmica e o Sucesso. Temas e Matizes, $n^{\circ}$ 05, julho de 2004, p. 55-61.

SUSSEKIND, Flora. Rodapés, Tratados e Ensaios - a formação da crítica brasileira moderna. In: . Papéis Colados. Rio de Janeiro: Editora UFRJ, 1993, p. 13-33.

TABORDA, Felipe (org.). A Imagem do Som de Chico Buarque - 80 artistas contemporâneos. Brasil: Francisco Alves, 1999.

TADIE, Jean-Yves. O Farol de Alexandria. In: A Crítica Literária no Século

XX. Rio de Janeiro: Bertrand do Brasil, 1992, p. 09-16.

TADIE, Jean-Yves. Os Formalistas Russos. In: A Crítica Literária no Século

XX. Rio de Janeiro: Bertrand do Brasil, 1992, p. 16-45.

TADIE, Jean-Yves. Sociologia da Literatura. In: A Crítica Literária no

Século XX. Rio de Janeiro: Bertrand do Brasil, 1992, p. 163-192.

WERNECK, Humberto (org.). Crônicas. São Paulo: Cia. das Letras, 2005.

WERNECK, Humberto (reportagem biográfica de Chico Buarque). Tantas Palavras. São Paulo, Companhia das Letras, 2006. 
WISNIK, José Miguel. O Som e o Sentido - Uma Outra História das Músicas. São Paulo: Cia. Das Letras, 1989.

WISNIK, José Miguel. A Gaia Ciência - Literatura e Música Popular no Brasil. In: Sem Receita. São Paulo: Publifolha, 2004, p. 215-259.

WISNIK, José Miguel. Veneno Remédio - O Futebol e o Brasil. São Paulo: Cia. Das Letras, 2008. 